\title{
EFFECT OF SOLUTION ENVIRONMENT ON DEAD-END MICROFILTRATION CHARACTERISTICS OF RUTILE SUSPENSIONS
}

\author{
EIJI IRITANI, YUKIHIKo TOYODA** AND TOSHIRo \\ MURASE \\ Department of Chemical Engineering, Nagoya University, Nagoya \\ 464-01
}

Key Words: Filtration, Microfiltration, Rutile, Filter Cake, Hydrophobic Colloid

\begin{abstract}
Microfiltration experiments were conducted under a constant pressure of $196 \mathrm{kPa}$, using a dead-end filter. The filtration properties were studied using titanium dioxide suspensions of the rutile form to determine the effects of such solvent environments as $\mathrm{pH}$ and the added salt. Both the average porosity and the average specific filtration resistance of the filter cake were determined. It was highlighted through this study that the electrical nature of particles depending on the solution environment plays a significant role in determining the structure of the filter cake which, in turn, influenced the filtration rate in microfiltration of dispersions of metal oxides. It was demonstrated unequivocally that the average porosity in the filter cake had a maximum and the average specific filtration resistance was minimal around the isoelectric $\mathrm{pH}$. These results were in contrast to those observed with ultrafiltration of protein solutions. Such charge effects of particles were weakened in the presence of salts.
\end{abstract}

\section{Introduction}

Cake filtration of suspensions of solid particles in aqueous solutions is frequently encountered in widely diversified fields. In cake filtration, the nature of the cake formed upon the membrane surface during filtration will govern the filtration rate of the remaining suspension. For fine particle suspensions, colloidal forces control the nature of the filter cake. Colloidal forces arise from interaction between the suspended particles. The two main colloidal forces are the attractive van der Waals forces which originate from fluctuating dipoles as a result of the motions of outer electrons on the interacting particles and the repulsive electrostatic forces due to the presence of like charges on the particles and a dielectric medium. Whilst for a given system the van der Waals forces are essentially constant, the electrostatic forces will vary with the surface charge of the suspended particles, which varies with the solution environment. Therefore, the filtration behaviors of the colloids are affected significantly by the solution properties, including $\mathrm{pH}$ and electrolyte strength. Although considerable work has been published on the effects of the solution environment on the filtration behaviors (Bacchin et al., 1995; 1996; Kawalec-Pietrenko and Ruszel-Lichodzijiewska, 1985; McDonogh et al., 1984; McDonogh et al., 1992; Shultz et al., 1983; Tarleton and Wakeman, 1994; Ueshima et al., 1991;

\footnotetext{
* Received on October 30, 1996. Correspondence concerning this article should be addressed to E. Iritani.

Presented at the 28th Autumn Meeting of The Society of Chemical Engineers, Japan, at Sapporo, September, 1995.

** Present Address: Ibiden Co. Ltd., Ogaki 503.
}

Welsch et al., 1995; Willmer et al., 1996), the underlying phenomena are currently not well understood.

In previous papers (Iritani et al., 1991; Iritani et al., 1992), it was found that the flux decline in protein ultrafiltration with retentive membranes was mainly attributable to the formation of a highly resistant filter cake due to accumulation of the protein solutes drawn toward the filtering surface by the convective flow of filtrate through the membrane. Moreover, it was found that the solution $\mathrm{pH}$ markedly affected the structure of the filter cake which, in turn, influenced the filtration rate in protein ultrafiltration. It is therefore essential to understand the nature of the filter cake in order to clarify the mechanisms of filtration of the colloids.

This article delineates the importance of the suspensions conditions in microfiltration of the particulate, mineral based suspensions by studying the dependence of the properties of the filter cake on the solution $\mathrm{pH}$ and the added salt, and hence the electrical charge of the particles. Unstirred dead-end microfiltration, in which we can avoid any need for knowledge or assumptions about the mechanics of fluid movement near the membrane surface, is conducted with retentive microfiltration membranes using dispersions of metal oxides. The objective of the study is to relate the filtration characteristics to the structural properties of the cake. In addition, an attempt is made to compare the filtration behaviors for microfiltration of the particulate suspensions with those for ultrafiltration of protein solutions. 


\section{Experimental}

\subsection{Materials}

The particle used in the experiments was titanium dioxide (Wako Pure Chemical Ind. Corp.) of the rutile form. This particle is an ampholytic dioxide, which has an isoelectric point as well as the protein molecule. All other reagents were analytical grade. Aqueous suspensions were prepared by suspending preweighed quantities of the particles in the pure water. The particle charge was adjusted by $\mathrm{pH}$ control. The solution $\mathrm{pH}$ was adjusted downward by the addition of $0.1 \mathrm{~N} \mathrm{HCl}$ solution and upward by the addition of $0.1 \mathrm{~N} \mathrm{NaOH}$ solution. To investigate the effect of salt on filtration behaviors, the salt concentration of the suspension was adjusted by the addition of $\mathrm{NaCl}$. Ultrapure, deionized water for solution make-up was prepared by an ultrapure water system for laboratory use (Puric-R, Olgano Corp.). The resistivity of this ultrapure, deionized water was 18 megohm.

Microfiltration membranes (VMWP) with a nominal pore size of $0.05 \mu \mathrm{m}$, supplied by Millipore Corp., were used for all microfiltration experiments.

\subsection{Experimental apparatus and technique}

An unstirred batch filtration cell with an effective membrane area of $19.6 \mathrm{~cm}^{2}$ was used in this research. Dead-end microfiltration experiments were carried out under conditions of constant pressure of $196 \mathrm{kPa}$ controlled by a reduction valve by applying compressed nitrogen gas after the suspensions were poured into the filter. The weight of the filtrate produced during filtration was measured with an electronic balance (Shimadzu Corp.) with a printer which was triggered at set intervals. The weights were converted to volumes using density correlations. The filtration rate was calculated as a function of filtration time $\theta$ and cumulative filtrate volume $v$ collected per unit effective membrane area. As soon as the whole slurry was filtered, both the mass $W_{\mathrm{w}}$ of the wet cake and the mass $W_{\mathrm{d}}$ of the dry cake were measured. Thus, the ratio $m$ of wet to dry cake mass was obtained by

$$
m=W_{\mathrm{w}} / W_{\mathrm{d}}
$$

The zeta potential of rutile particles was determined by measuring the particle electrophoretic mobility with a particle microelectrophoresis apparatus (Model 5-17, Mitamura Riken Ind. Corp.). Also, the mass-based size distributions of rutile particles were determined using a laser granulometer (Model HR850, Compagnie Industrielle Des Lasers). The specific gravity of the particles was measured by, using an air comparison pycnometer (Model 930, Beckmann-Toshiba Corp.).

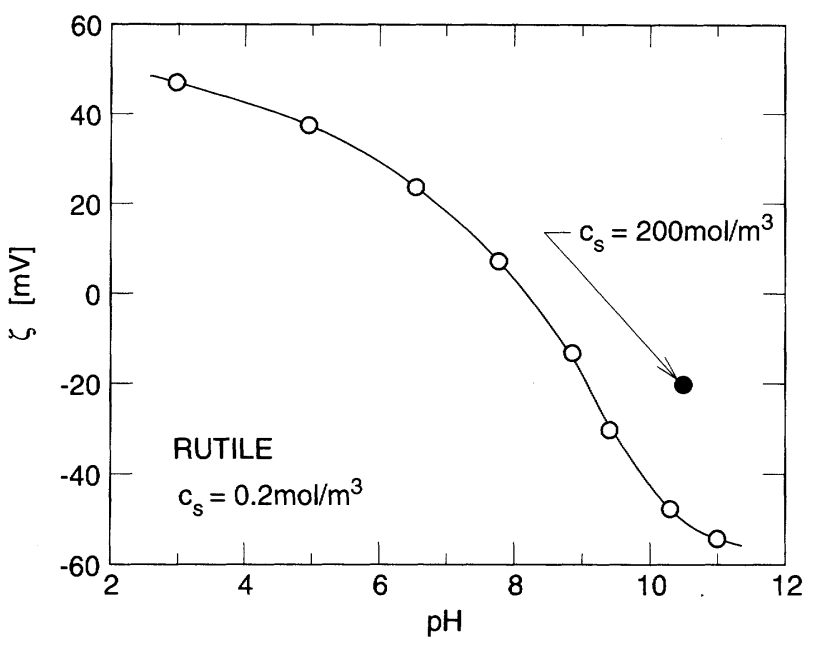

Fig. 1 Zeta potential for rutile as function of $\mathrm{pH}$

\section{Results and Discussion}

\subsection{Properties of rutile particles}

The surface charge properties of rutile powder in aqueous suspensions were generally determined in terms of the zeta potential using the particle microelectrophoresis apparatus. Figure 1 shows a typical zeta potential vs. $\mathrm{pH}$ curve obtained for the rutile powder. The surface charge on metal oxides is established by the amphoteric reaction of the surface hydroxyl groups with $\mathrm{H}^{+}$or $\mathrm{OH}^{-}$(Liddell and Boger, 1994), and hence the zeta potential of rutile particles is $\mathrm{pH}$ dependent. It is clear from the figure that the isoelectric point of the rutile particle, where the particle carries no charge, is at ca. 8.1. The particle has a positive charge at $\mathrm{pH}$ lower than isoelectric $\mathrm{pH}$ and a negative charge at $\mathrm{pH}$ higher than isoelectric $\mathrm{pH}$. It can be also seen that the magnitude of the zeta potential decreases markedly by the addition of salt at the same $\mathrm{pH}$.

Figure 2 shows the particle size distributions of the rutile particles measured by laser granulometer. In this graph, the frequency $f$ is plotted against the particle diameter $d_{\mathrm{p}}$. At $\mathrm{pH} 4.5$, the particles in suspension maintain a dispersed state, and the original mean specific surface area size of the particles is $0.47 \mu \mathrm{m}$. The presence of a significant surface charge at the interface between particle and liquid promotes the stability of a colloidal dispersion. In contrast, at pH 7.9 around the isoelectric point, the rutile suspension favors the flocculated state due to van der Waals attractive force because the particle carries no charge. Thus, the mean size of aggregated rutile particles is $4.5 \mu \mathrm{m}$, and it is much larger than the original mean particle size. Also at $\mathrm{pH} 10.5$, the addition of salt destabilizes the suspension, and thus the particles flocculate. 


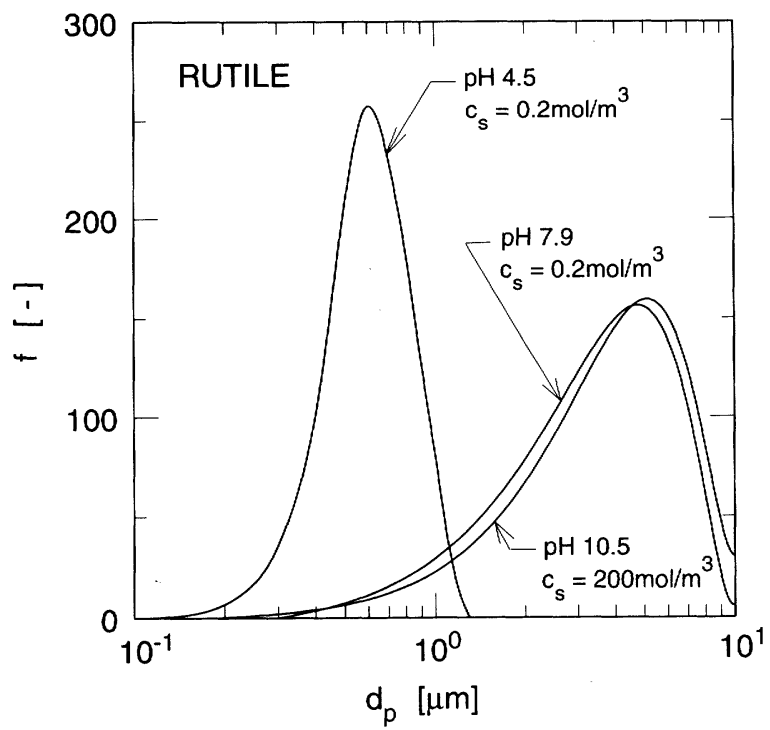

Fig. 2 Particle size distributions

\subsection{Analysis of filtration data}

If sedimentation during filtration is negligible, the filtration rate equation can be described by (Ruth, 1935; 1946)

$$
\frac{d \theta}{d v}=\frac{\mu \alpha_{\mathrm{av}} \rho s}{p(1-m s)}\left(v+v_{\mathrm{m}}\right)
$$

where $\mu$ is the viscosity of the filtrate, $\alpha_{\mathrm{av}}$ is the average specific filtration resistance, $\rho$ is the density of the filtrate, $s$ is the mass fraction of the solid in the slurry, $p$ is the applied filtration pressure, and $v_{\mathrm{m}}$ is the fictitious filtrate volume per unit membrane area, equivalent to the flow resistance of the membrane. In Fig. 3, the results of the filtration experiments for three different values of $\mathrm{pH}$ are plotted in the form of the reciprocal filtration rate $(d \theta / d v)$ against $v$. At $\mathrm{pH} 4.5$, the particles are likely to be well dispersed, and thus the effect of settling of particles during filtration is negligible. The plot is well known as the Ruth plot (Ruth, 1935; 1946) in classical cake filtration. The filtration data appeared to be linear in accordance with Eq. (2). However, after the whole slurry was filtered, the value of the reciprocal filtration rate increased sharply. The average specific filtration resistance $\alpha_{\mathrm{av}}$ can be calculated from Eq. (2) by using the slope of the plot of $d \theta / d v$ against $v$ and the value of $m$. The average porosity $\varepsilon_{\mathrm{av}}$ of the filter cake can be obtained by (Iritani et al., 1995)

$$
\varepsilon_{\mathrm{av}}=\frac{(m-1) \rho_{s}}{\rho+(m-1) \rho_{s}}
$$

where $\rho_{s}$ is the true density of the solids. The value of $\rho_{s}$ of the rutile particles was $4.73 \times 10^{3} \mathrm{~kg} / \mathrm{m}^{3}$. Also at

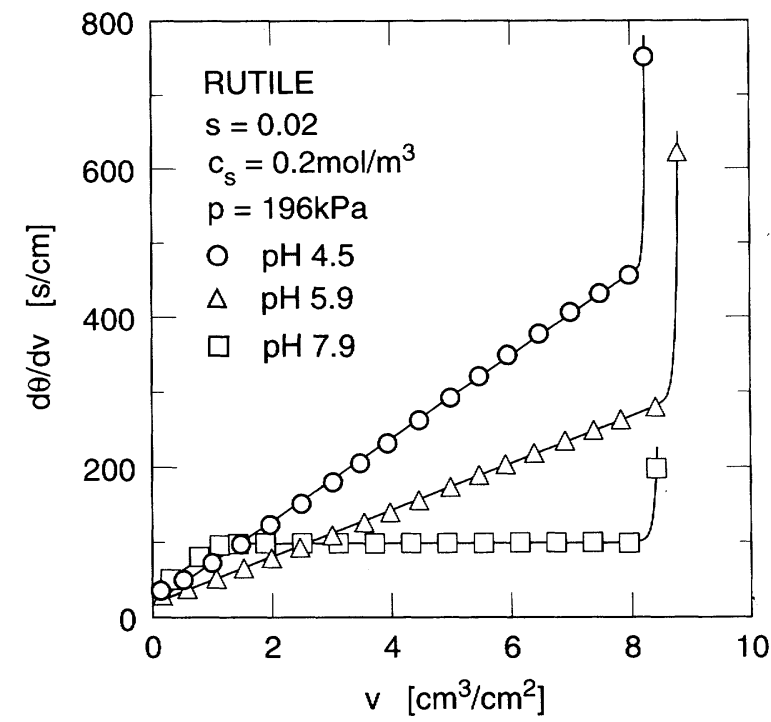

Fig. 3 Relation between reciprocal filtration rate and filtrate volume per unit membrane area

$\mathrm{pH} 5.9, \alpha_{\mathrm{av}}$ and $\varepsilon_{\mathrm{av}}$ can be obtained by the same method.

However, the result at $\mathrm{pH} 7.9$, where the charge at the particle surface is close to the isoelectric point, is in contrast to that at $\mathrm{pH} 4.5$. At the beginning of the experiment, the filtration rate decreased with time in response to the formation of the filter cake on the membrane surface. It was observed that, in this period, filtration was accompanied by settling since the particles were destabilized at that $\mathrm{pH}$. Consequently, after the formation of the filter cake was completed, the supernatant fluid permeated through the filter cake. In this period, the value of $d \theta / d v$ remained approximately constant. After permeation was completed, the value of $d \theta / d v$ increased sharply. From the value of this constant reciprocal filtration rate $(d \theta / d v)_{\mathrm{p}}$, the average specific filtration resistance $\alpha_{\text {av }}$ can be obtained by

$$
\alpha_{\mathrm{av}}=\frac{p}{\mu w}\left\{\left(\frac{d \theta}{d v}\right)_{\mathrm{p}}-\left(\frac{d \theta}{d v}\right)_{\mathrm{m}}\right\}
$$

where $w$ is the net solid mass of the entire filter cake per unit effective membrane area, and $(d \theta / d v)_{\mathrm{m}}$ is the reciprocal filtration rate, equivalent to the flow resistance of the membrane, and it is equal to the reciprocal filtration rate at the start of filtration.

\subsection{Effect of $\mathbf{p H}$}

Figure 4 shows the average specific filtration resistance $\alpha_{\mathrm{av}}$ and the average porosity $\varepsilon_{\mathrm{av}}$ of the filter cake formed in microfiltration of the rutile suspensions at different values of $\mathrm{pH}$ under otherwise identical filtration conditions. It should be noted that the resistance $\alpha_{\mathrm{av}}$ is a measure of the filterability of the suspensions. A larger $\alpha_{a v}$ causes a smaller 


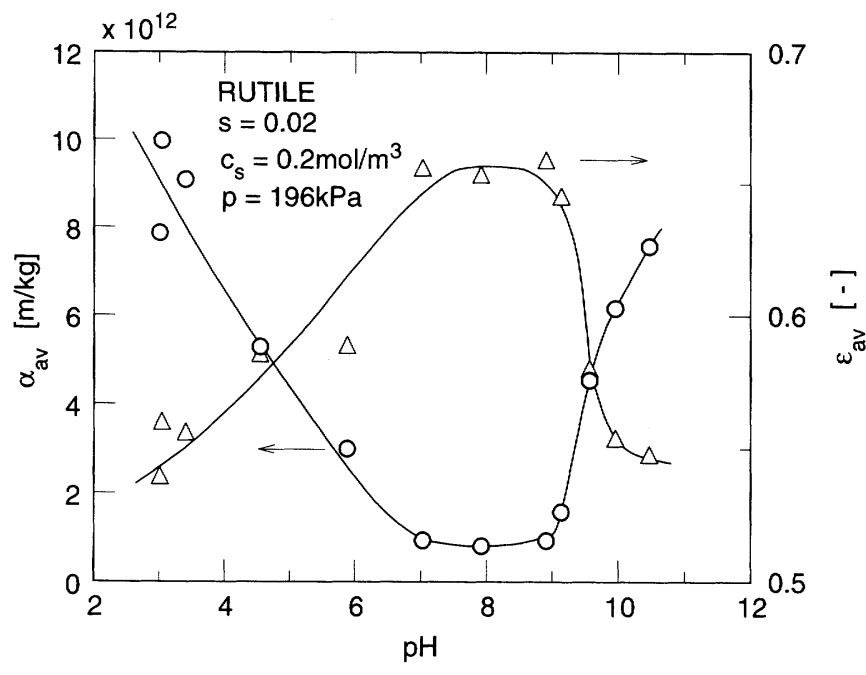

Fig. 4 Dependence of average specific filtration resistance and average porosity of filter cake on solution $\mathrm{pH}$

filtration rate. It can be seen that $\alpha_{\mathrm{av}}$ goes through a minimum around the isoelectric point. Thus, the largest filtration rate can be obtained when the particle carries no charge. Tarleton and Wakeman (1994) reported similar results for crossflow microfiltration of anatase suspension. However, this result is in sharp contrast to that obtained in protein ultrafiltration (Iritani et al., 1991; Iritani et al., 1992). It is clear that $\varepsilon_{\mathrm{av}}$ is much larger near the isoelectric $\mathrm{pH}$. Since the rutile particles are hydrophobic colloids, they are destabilized around the isoelectric point where the van der Waals attraction is more dominant. Consequently, the particles will tend to come together, i.e. to flocculate, and the very porous flocs are then formed. Thus, the authors speculate that the filter cake formed from such porous flocs has often loose and wet structure. On the other hand, the filter cake becomes compact and dry when the particle carries the charge. Since the most loose filter cake forms around the isoelectric $\mathrm{pH}$, the filter cake is most permeable. Thus $\alpha_{\mathrm{av}}$ is much smaller near the isoelectric point.

In Fig. 5, the average specific filtration resistance $\alpha_{\mathrm{av}}$ is plotted against the average porosity $\varepsilon_{\mathrm{av}}$ of the filter cake. This figure indicates that in general the increase of the resistance $\alpha_{\mathrm{av}}$ roughly corresponds to the decrease of the porosity $\varepsilon_{\mathrm{av}}$.

It is interesting to note that the results in protein ultrafiltration had a distinctly different behavior. In protein ultrafiltration of bovine serum albumin (BSA) solution, it has previously been reported that the filter cake is in its most compact state around the isoelectric point (results not shown; see ref. Iritani et al., 1991; Iritani et al., 1992). Since the BSA molecules are hydrophilic colloids, their stability in the solution would appear to be influenced not only by the

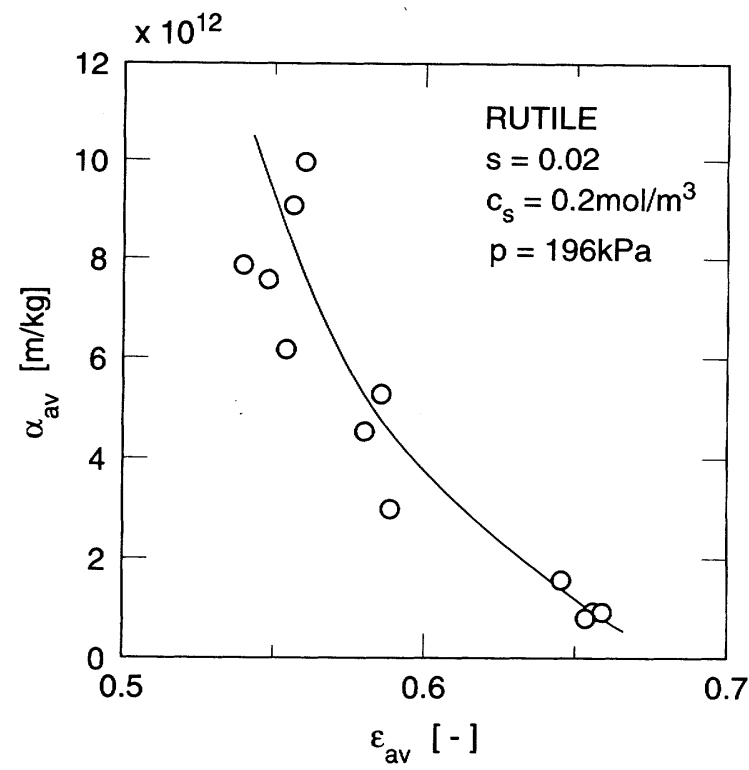

Fig. 5 Relation between average specific filtration resistance and average porosity

presence of a surface charge on the protein but also by hydration of the surface layers of the protein. The BSA molecules, because of hydrated layers surrounding them, are not destabilized by such considerations as depression of the electrical double layer. Thus, the BSA molecules have water bound to them even around the isoelectric point. The hydrophilic BSA molecules maintain a dispersed state in the solution due to hydration of the surface layers of the protein, even around the isoelectric point. When a BSA molecule acquires a charge, the filter cake becomes loose and wet due to electrostatic repulsion between the charged BSA molecules. This contrasts to the compact filter cake around the isoelectric point.

Figure 6 illustrates how the mean specific surface area size $d_{\mathrm{s}}$ of the particles can influence the average porosity $\varepsilon_{\mathrm{av}}$ of the filter cake. The cake porosity increases with the particle size because porous flocs form. But, porosity varies little with particle size in the range of particle sizes larger than $0.8 \mu \mathrm{m}$.

In Fig. 7, the average porosity $\varepsilon_{\mathrm{av}}$ is plotted against absolute values of zeta potentials. This figure shows a close relation between $\varepsilon_{\text {av }}$ and the zeta potential. It is surprising that the plots can be represented by a unique curve irrespective of the sign of the zeta potential. The cake porosity increases with decreasing zeta potential. The porosity remains constant in the range of the zeta potential below ca. $20 \mathrm{mV}$. As the zeta potential decreases, the electrostatic repulsion decreases and thus the porous floc forms. Therefore, the average porosity of the filter cake increases.

In Fig. 8, the average specific filtration resistance $\alpha_{\mathrm{av}}$ of the filter cake is plotted against absolute values 


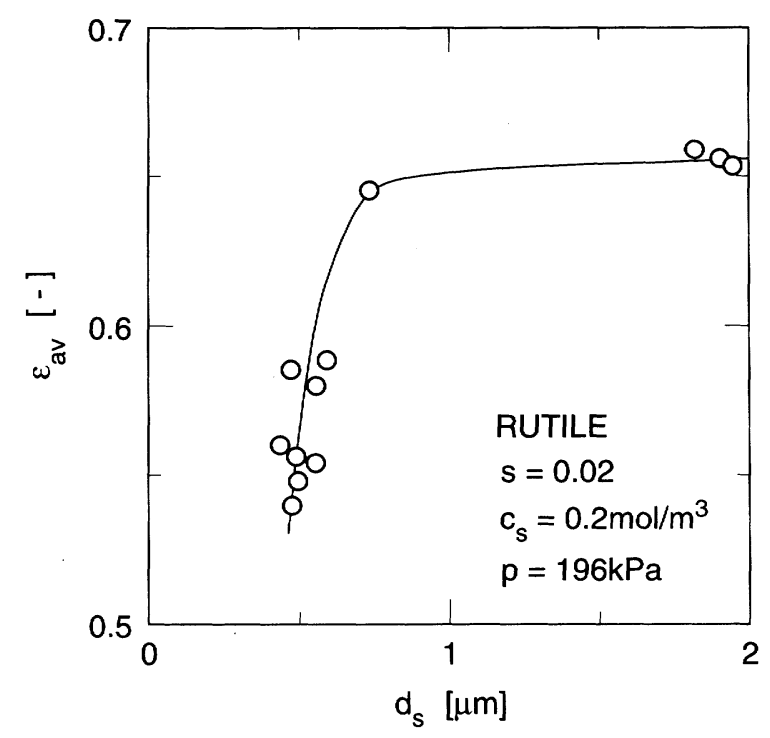

Fig. 6 Relation between average porosity of filter cake and mean specific surface area size of particles

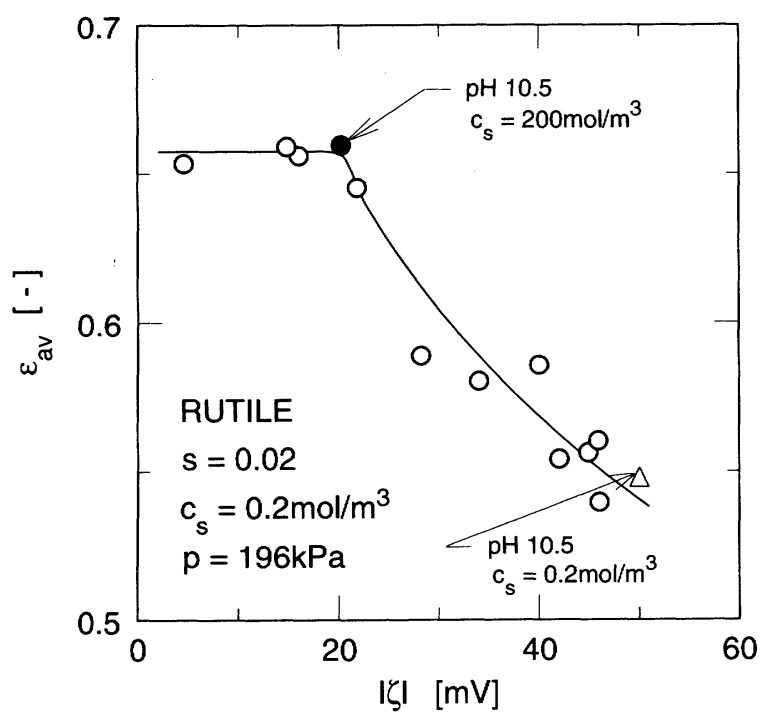

Fig. 7 Relation between average porosity of filter cake and absolute value of zeta potential

of zeta potentials. It appears that a decreased zeta potential can readily induce a lower resistance $\alpha_{\text {av }}$. But, $\alpha_{\mathrm{av}}$ is relatively independent of the zeta potential in the range of the zeta potential below ca. $20 \mathrm{mV}$.

\subsection{Effect of added salt}

The repulsive force that stems from the overlapping of the electric double layers, depends on the presence or absence of ionized salt in suspension. The repulsive force is less effective at higher ion concentrations and can't counteract the van der Waals attraction, and so the solution flocculates. Therefore, it is conceivable that the filtration rate is markedly influenced not only by the solution $\mathrm{pH}$ but also by the solution ionic strength. The result for the

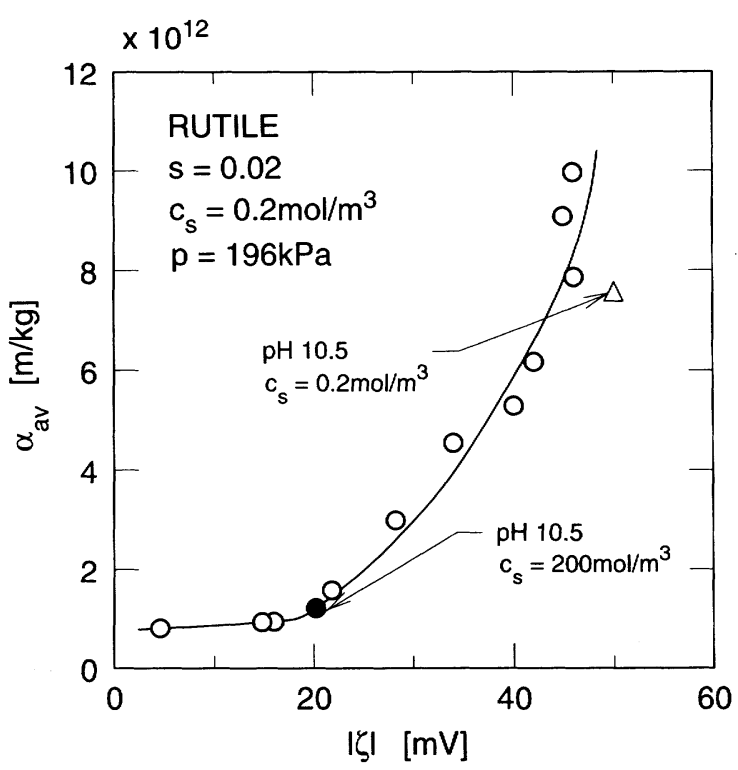

Fig. 8 Relation between average specific filtration resistance and absolute value of zeta potential

$\mathrm{NaCl}$ concentration of $200 \mathrm{~mol} / \mathrm{m}^{3}$ at $\mathrm{pH} 10.5$ is shown in Fig. 7. The magnitude of the zeta potential decreased remarkably as a result of the addition of $\mathrm{NaCl}$ compared with that for the $\mathrm{NaCl}$ concentration of $0.2 \mathrm{~mol} / \mathrm{m}^{3}$ at the same $\mathrm{pH}$. The average porosity $\varepsilon_{\mathrm{av}}$ of the filter cake is augmented markedly by the addition of salt. This is because the addition of salt destabilizes the suspension by reducing the double layer repulsion between rutile particles, as shown in Fig. 2. It should be emphasized that the plot for the $\mathrm{NaCl}$ concentration of $200 \mathrm{~mol} / \mathrm{m}^{3}$ lies on the unique curve. On the other hand, the data illustrated in Fig. 8 show that the average specific filtration resistance $\alpha_{\mathrm{av}}$ decreases remarkably by the addition of the salt at the same $\mathrm{pH}$. The plot for $\mathrm{NaCl}$ concentration of $200 \mathrm{~mol} / \mathrm{m}^{3}$ lies on a unique curve representing the relation between $\alpha_{\mathrm{av}}$ and the zeta potential.

\section{Conclusion}

Experimental data of unstirred dead-end microfiltration have been obtained by using a titanium dioxide suspension of the rutile form. Such basic properties of the filter cake as the average porosity $\varepsilon_{\mathrm{av}}$ and the average specific filtration resistance $\alpha_{\mathrm{av}}$ were measured. The effects of the solution $\mathrm{pH}$ and the presence of salts of the solution environment surrounding the particles on such filter cake properties were explored. The data shown in this paper clearly indicate that the electrostatic interactions between the suspended particulates depending on the solution $\mathrm{pH}$ may control the properties of the filter cake. It has been shown that the average porosity in the filter cake has a maximum and the average specific filtration 
resistance is minimal around the isoelectric $\mathrm{pH}$. These results are in contrast to those for ultrafiltration of BSA solutions. The charge effects of particles were weakened when salts were added.

\section{Acknowledgment}

The authors would like to acknowledge the valuable suggestions and guidance of Dr. Masayuki Nakagaki of Tokyo Institute of Colloid Science.

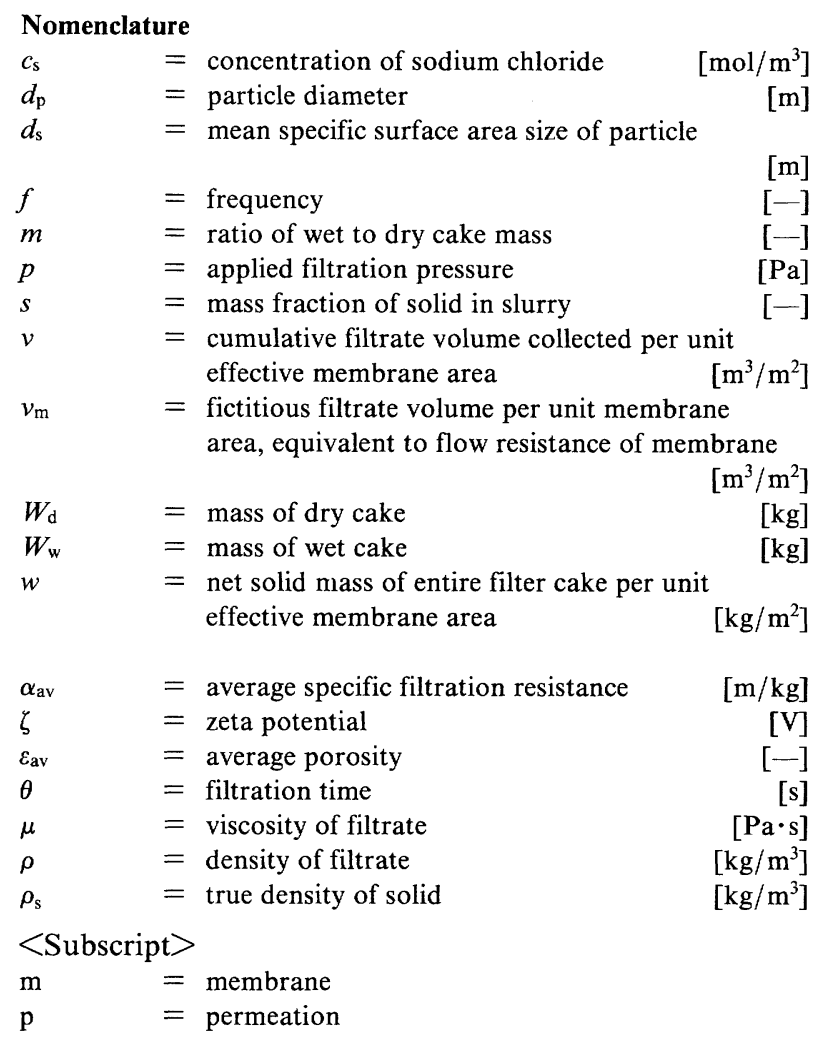

\section{Literature Cited}

Bacchin, P., P. Aimar and V. Sanchez; "Model for Colloidal Fouling of Membranes," AIChE J., 41, 368-376 (1995)

Bacchin, P., P. Aimar and V. Sanchez; "Influence of Surface Interaction on Transfer during Colloid Ultrafiltration," J. Membrane Sci., 115, 49-63 (1996)
Iritani, E., S. Nakatsuka, H. Aoki and T. Murase; "Effect of Solution Environment on Unstirred Dead-End Ultrafiltration Characteristics of Proteinaceous Solutions," J. Chem. Eng. Japan, 24, 177-183 (1991)

Iritani, E., T. Watanabe and T. Murase; "Effects of pH and Solvent Density on Dead-End Upward Ultrafiltration," J. Membrane Sci., 69, 87-97 (1992)

Iritani, E., Y. Mukai and T. Murase; "Properties of Filter Cake in Dead-End Ultrafiltration of Binary Protein Mixtures with Retentive Membranes," Trans. IChemE, 73A, 551-558 (1995)

Kawalec-Pietrenko, B. and R. Ruszel-Lichodzijiewska; "The Influence of Physico-Chemical and Operating Parameters on the Filtration of Precipitate of Hydrated $\mathrm{Zr}$ (IV) Oxide," J. Chem. Tech. Biotechnol., 35A, 426-430 (1985)

Liddell, P.V. and D.V. Boger; "Influence of Processing on the Rheology of Titanium Dioxide Pigment Suspensions," Ind. End. Chem. Res., 33, 2437-2442 (1994)

McDonogh, R.M., C.J.D. Fell and A.G. Fane; "Surface Charge and Permeability in the Ultrafiltration of Non-Flocculating Colloids," J. Membrane Sci., 21, 285-294 (1984)

McDonogh, R.M., K. Welsch, A.G. Fane and C.J.D. Fell; "Incorporation of the Cake Pressure Profiles in the Calculation of the Effect of Particle Charge on the Permeability of Filter Cakes Obtained in the Filtration of Colloids and Particulates," J. Membrane Sci., 72, 197-204 (1992)

Ruth, B.F.; "Studies in Filtration. III. Derivation of General Filtration Equations," Ind. End. Chem., 27, 708-723 (1935)

Ruth, B.F.; "Correlating Filtration Theory with Industrial Practice," Ind. Eng. Chem., 38, 564-571 (1946)

Schultz, J., E. Papirer and M. Nardin; "Physicochemical Aspects of the Filtration of Aqueous Suspensions of Fibers and Cement. 4. Influence of the $\zeta$ Potential of the Fibers on Filtration Efficiency," Ind. Eng. Chem. Prod. Res. Dev., 22, 102-105 (1983)

Tarleton, E.S. and R.J. Wakeman; "Understanding Flux Decline in Crossflow Microfiltration: Part II - Effects of Process Parameters," Trans. IChemE, 72A, 431-440 (1994)

Ueshima, K., H. Iizuka and K. Higashitani; "Ordered Structure of Monodispersed Particles Filtered at Constant Pressure," J. Chem. Eng. Japan, 24, 647-652 (1991)

Welsch, K., R.M. McDonogh, A.G. Fane and C.J.D. Fell; "Calculation of Limiting Fluxes in the Ultrafiltration of Colloids and Fine Particulates," J. Membrane Sci., 99, 229-239 (1995)

Willmer, S.A., E.S. Tarleton and R.G. Holdich; "The Importance of Cake Compressibility in Deadend Pressure Filtration," Proc. 7th World Filtration Congress, Vol. I, p. 27-31, Hungarian Chemical Society, Budapest, Hungary (1996) 